\title{
Harnessing Insight into Disciplinary Differences to Refine e-learning Design
}

\author{
$\mathrm{Su}$ White and Ilaria Liccardi \\ Electronic and Computer Science, University of Southampton, \\ Southampton, SO17 1BJ, UK. saw@ecs.soton.ac.uk, i105r@ecs.soton.ac.uk
}

\begin{abstract}
Many different teaching methods are used to support learning in higher education. Research into the relationship between the knowledge traditions of fields of study and their most appropriate teaching methods identifies clear differences between the appropriate which are the most suitable in different disciplines. Increasingly, blended approaches to education are being introduced, integrating e-learning with face-to face methods. However, major influences on our understanding of the potential of e-learning have come from psychological and educational perspectives, which are not, of themselves, clearly associated with specific disciplinary needs. This paper identifies e-learning approaches which particularly suit specific disciplinary preferences. It surveys students to identify methods which they believe are particularly relevant to their studies. Their responses support the case for taking a disciplinary perspective when developing blended approaches.
\end{abstract}

Index Terms -Disciplinary Differences, e-learning, higher education, technology affordances.

\section{INTRODUCTION}

Research into the knowledge traditions of different fields of study identifies clear differences between four discrete categories of hard or soft and pure or applied [1-3] Appropriate teaching methods vary according to academic discipline [3-8] and will take into account academic level and prior experience of the learners, and the mode of attendance. Blended learning combines e-learning and face-to-face methods. The particular mix of each method may be tuned to match the educational needs of the learner, providing an opportunity to utilise to the best advantage the relative strengths of these two different styles of learner contact. Insights into the relative strengths and suitability of particular approaches can be helpful to faculty when designing the curriculum and implementing educational innovations.

This paper analyses how knowledge of disciplinary differences can be used to inform the selection, design and integration of appropriate e-learning activities. It uses survey data from undergraduate and postgraduate students to provide a perspective on the analysis. The paper outlines ways in which analysing and understanding disciplinary differences can be used to create a conceptual framework for the analysis of educational approaches suitable for specific discipline areas. It then goes on to analyse approaches to e-learning in the context of what has been observed and learnt from the study of disciplinary differences. It reports on the analysis of a survey of students' attitudes to e-learning. The survey compares the student responses to a theoretical framework suggested by the disciplinary differences categorisation. The survey covers students perceptions of the relative importance of e-learning methods associated with the knowledge and teaching approaches associated with specific areas of study. Although the framework for disciplinary differences applies across all fields of study, the analysis in the final sections of this paper offers reflections and conclusions which are specific to teaching and the support of learning in engineering and its cognate subject areas. The paper concludes be examining the implications of the framework from two perspectives of student learning and curriculum innovation.

\section{UNDERSTANDING DISCIPLINARY DIFFERENCES}

The foundations of scholarship concerned with understanding disciplinary differences was begun by Biglan who undertook a conceptual analysis of subject approaches. He looked at the characteristics of subject matter in different scientific areas [1, 2]. Neumann Parry and Becher [5] brought together findings from a wide range of consequential studies, and extended Biglan's approach by carrying out a conceptual analysis of teaching and learning activities based around Biglan's earlier categorisation.

\section{Academic Fields of Study}

Broadly, academic fields of study are analyzed within two significant sub-groupings. Discipline areas are considered to be either hard or soft, and then either pure or applied. It is acknowledged that some disciplines (or particular specialisms within the discipline) may straddle either of these boundaries. In addition subjects may, over time, migrate towards one area from another; for example the movement of linguistics into the hard pure area through the increased influence of computational research. Neumann Parry and Becher's study identified ways in which teaching and the assimilation of knowledge is achieved. Within each discipline it is possible to derive a profile of the field of study through two perspectives:

- knowledge related: curriculum, assessment, main cognitive purpose;

- socially related: teachers' characteristics, teaching methods, implicit requirements of students.

October 28 - 31, 2006, San Diego, CA 
Session S3J

They argue that "a sound understanding of key aspects of teaching and learning must depend on the recognition of the distinctive features of different knowledge domains and their social mileiux".

The knowledge tradition in hard areas is defined as atomistic, cumulative and quantitative. There is a strong sense of superseded knowledge, universals and simplification, research is typically competitive but gregarious, with many researchers working and publishing collaboratively. By contrast knowledge in soft areas is defined as holistic, reiterative and qualitative. There is no sense of superseded knowledge. Researchers in soft fields of study typically undertake solitary scholarly enquiry and there is limited overlap between researchers' areas of interest. A summary of the knowledge related perspective derived from this analysis is shown below (Table I).

TABLE I. MAPPING DISCIPLINARY AREAS

\begin{tabular}{|c|c|c|c|}
\hline & $\begin{array}{l}\text { Curriculum / } \\
\text { Content }\end{array}$ & Assessment & $\begin{array}{l}\text { Cognitive } \\
\text { Purpose }\end{array}$ \\
\hline $\begin{array}{l}\text { HARD- } \\
\text { PURE } \\
\text { e.g. } \\
\text { Natural } \\
\text { Sciences }\end{array}$ & $\begin{array}{l}\text { Concepts and } \\
\text { principles are } \\
\text { closely } \\
\text { connected. } \\
\text { Content typically } \\
\text { fixed and } \\
\text { cumulative. } \\
\text { Quantitative. } \\
\text { Teaching and } \\
\text { learning } \\
\text { activities are } \\
\text { focused and } \\
\text { instructive. }\end{array}$ & $\begin{array}{l}\text { Specific and } \\
\text { focused exam } \\
\text { questions. } \\
\text { Objective tests } \\
\text { relying on } \\
\text { quantitative } \\
\text { nature of } \\
\text { knowledge }\end{array}$ & $\begin{array}{l}\text { Logical } \\
\text { reasoning. } \\
\text { Testing of ideas } \\
\text { in linear form of } \\
\text { argumentation. } \\
\text { Reliance on } \\
\text { facts, principles, } \\
\text { and concepts. }\end{array}$ \\
\hline $\begin{array}{l}\text { HARD } \\
\text { APPLIED } \\
\text { e.g. } \\
\text { Engineering }\end{array}$ & $\begin{array}{l}\text { Concerned with } \\
\text { the mastery of } \\
\text { the physical } \\
\text { environment } \\
\text { Focus is on } \\
\text { products and } \\
\text { techniques } \\
\text { Knowledge is } \\
\text { atomistic and } \\
\text { cumulative } \\
\text { emphases factual } \\
\text { understanding }\end{array}$ & $\begin{array}{l}\text { Preference for } \\
\text { exam } \\
\text { questions, } \\
\text { especially } \\
\text { problem- } \\
\text { solving }\end{array}$ & $\begin{array}{l}\text { Problem-solving } \\
\text { and practical } \\
\text { skills Emphasis } \\
\text { on integration } \\
\text { and application } \\
\text { of existing } \\
\text { knowledge }\end{array}$ \\
\hline $\begin{array}{l}\text { SOFT- } \\
\text { PURE } \\
\text { e.g. } \\
\text { Social } \\
\text { Sciences and } \\
\text { Humanities }\end{array}$ & $\begin{array}{l}\text { Non-linear, open } \\
\text { and loose } \\
\text { Content is free- } \\
\text { ranging } \\
\text { Qualitative } \\
\text { Teaching and } \\
\text { learning } \\
\text { activities are } \\
\text { constructive and } \\
\text { interpretative }\end{array}$ & $\begin{array}{l}\text { Essay } \\
\text { questions, } \\
\text { short answer } \\
\text { questions, and } \\
\text { oral } \\
\text { presentations } \\
\text { Ongoing } \\
\text { assessment }\end{array}$ & $\begin{array}{l}\text { Broad command } \\
\text { of intellectual } \\
\text { ideas Emphasis } \\
\text { on creativity in } \\
\text { thinking and } \\
\text { fluency of } \\
\text { expression }\end{array}$ \\
\hline $\begin{array}{l}\text { SOFT } \\
\text { APPLIED } \\
\text { e.g. } \\
\text { Nursing, } \\
\text { Education }\end{array}$ & $\begin{array}{l}\text { Concerned with } \\
\text { the enhancement } \\
\text { of professional } \\
\text { practice } \\
\text { Knowledge is } \\
\text { reiterative and } \\
\text { holistic }\end{array}$ & $\begin{array}{l}\text { Essays, } \\
\text { project-based } \\
\text { assignments } \\
\text { Use of peer } \\
\text { and self- } \\
\text { assessment } \\
\text { tasks }\end{array}$ & $\begin{array}{l}\text { Emphasis on } \\
\text { personal growth } \\
\text { and intellectual } \\
\text { breadth } \\
\text { Development of } \\
\text { reflective } \\
\text { practice and } \\
\text { lifelong learning } \\
\text { skills }\end{array}$ \\
\hline
\end{tabular}

1-4244-0257-3/06/\$20.00 C 2006 IEEE
These knowledge foundations are true in both the pure and applied context, however in the applied field additional behaviors are observed. Knowledge communities in the hard applied area are expected to achieve mastery of the physical environment, and valued skills are geared towards products and techniques. In soft applied communities emphasis is placed on enhancement of professional practice and competency in professional protocols and procedures. These foundations determine the knowledge and understanding which is desired of successful students and thus determine the mix of teaching methods.

\section{Possible Implications}

The focus of our academic community lies in the hard applied tradition of engineering and to a lesser extent the knowledge traditions of the hard pure world of the natural sciences. An explicit awareness of the different requirements specific to each of the four broad areas can be harnessed by those within our specialisms who have a particular interest in achieving educational change. The framework can be used to inform decisions related to curriculum design and pedagogic innovations. Each of the types of approaches outlined in the table above relate to general educational methods. However the framework could also be used to identify different types of e-learning implementation which match the educational methods. .

Concluding on the implications of their framework, Neumann Parry and Becher specifically express concerns that some teaching innovation has been subject to an "indiscriminatory eagerness to embed methods found effective in one discipline area into other less amenable fields". This observation may have special resonance to those who are making curricular changes which involve e-learning and blended learning. These matters are explored in further detail in the next section.

\section{APPROACHES TO E-LEARNING}

The use of modern computers in education and training began with military applications and developed alongside the technology through successive generations of hardware design. Higher Education was influenced by a number of seminal publications in the 1990s when a constructivist viewpoint came to the fore [9-12]. Debate focussed on achieving active learning, and much was made or the role of dialogue in the learning process. One way of representing the components of computer based learning, within the framework of pursuing active learning is shown below (Figure 1) in the form of an activity gradient. The basis for the activity gradient shown above was originally derived from an analysis of Laurillard's conversational model [9] and Mayes concepts of primary, secondary and tertiary software cumulatively increasing the level of student engagement which could in turn support learning through the "iterative refinement of understanding" [13]. The activity gradient describes the types of activity (presentation, collection, interaction, production and communication) and also the educational approach (didactic, reflective, participative, experiential, discursive). The activity gradient was initially applied to the area of

\section{$36^{\text {th }}$ ASEE/IEEE Frontiers in Education Conference

October 28 - 31, 2006, San Diego, CA 
Session S3J

language learning but has also been applied to support elearning design decisions in cross disciplinary e-learning contexts $[14,15]$.

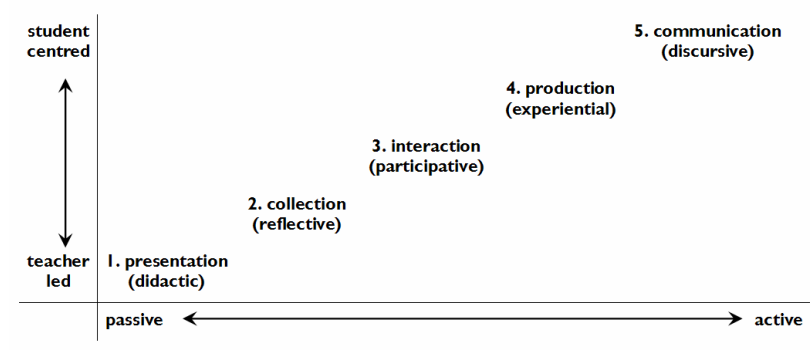

FIGURE 1. THE ACTIVITY GRADIENT WITH TEACHING APPROACHES

The activity gradient is elaborated by the inclusions of indicative activities below (Figure 2). Virtual Learning Environments (VLEs) are shown as an encapsulation tool which can encompass any or all of the technologies on the gradient, although they also have the potential to introduce a level of management and information organization which does not appear in the basic version of the gradient.

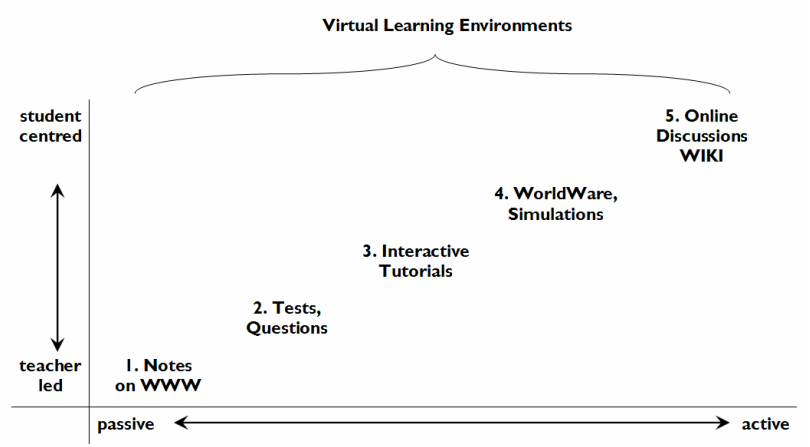

\section{FIGURE 2. THE ACTIVITY GRADIENT WITH EXAMPLES OF LEARNING ACTIVITIES}

These diagrams represent an overview of technology affordances [16]. Technology affordances are the activities and processes supported or encouraged (afforded) by the particular technology. Technology affordances in education are often discussed at a high level. For instance the literature on computer mediated communication has made much of its ability to support and engender dialogue, early uses of computer based training emphasised the ability of the computer to individually pace and guide the learner

It is possible to compare the stages on the activity gradient with the analysis of knowledge perspective shown in Table 1. Taking into account observations of Neumann Parry and Becher on the possible shortcomings of indiscriminate transfer of methods between discipline areas, a useful approach to curriculum design and innovation might be to identify technology affordances with reference to the fields of study in which they are to be constructively applied. Below we identify indicative uses of e-learning which exploit relevant affordances and relate these to the steps in the activity gradient and the knowledge perspective. Knowledge foundations are shared by pure and applied subjects, so the emphasis on this categorisation primarily differentiates between hard and soft fields of study.

\section{Presentation, Didactic}

Hard subjects based on facts, theories and the accumulation of knowledge can make good use of electronically published or distributed study guides and similar online material. Soft subjects approach knowledge in a holistic, constructive and interpretive manner. E-learning may be appropriate for pointing to external resources or presenting facsimiles of authentic sources.

\section{Collection, Reflective}

Reflection: Hard subjects are typically quantitative. This approach is well suited to make use of Computer Assisted Assessment for objective tests, both for stage tests and as self test questions. Soft subjects are typically qualitative may use technology to create electronic portfolios or blogs which can be submitted for conventional marking, however, automated marking does not easily work with this knowledge style.

\section{Interaction, Participative}

Hard subjects are concerned with mastery, teaching is often intensive. This may be served by using classic computer based learning or courseware which delivers and paces material to the learner. Soft Subjects place less emphasis on knowledge foundations, however they may use a computer based learning approach at a basic level dealing with discrete areas of the curriculum, but it does not match the more common open and fluid style of knowledge acquisition which is core to soft fields of study.

\section{Production, Experiential}

Hard subjects place emphasis on logical reasoning and the testing of ideas. In applied areas problem solving and practical skills are also important. Models, simulations and visualisations can be used to provide the learner with opportunities to observe, apply and test out theories. Soft subjects demand a broad command of intellectual ideas, creative thinking and fluency of expression. The use of various web publishing formats can allow learners to develop and demonstrate the development of their critical thinking skills.

\section{Communication, Discursive}

Hard subjects rely on facts, principles and concepts and place a greater emphasis on mastery of the content than the discussion of understanding. In applied areas the capabilities of email, wikis and discussion boards to convey problem statements and facilitate collaborative problem solving is 


\section{Session S3J}

relevant. Soft subjects require students to develop skills of interpretation and critical thinking and have a facility in oral and written expression, online discussion facilities of all types can be used to support this aspect. They can facilitate reflection, which is an important aspect of critical thinking and in applied areas is a key component of soft professional skills.

\section{Virtual Learning Environments}

These are no more than encapsulations of a number of different e-learning applications. In many ways their affordances are similar to those of classic courseware. In hard subjects where knowledge is atomistic, sequential and cumulative they may be useful in ordering and organising information. In soft subjects which are holistic, constructive and interpretive they may be used to integrate different elearning tools to construct a specific learning activity, for example linking web publishing with an online discussion.

\section{Additional Observations}

It was observed in Neumann Parry and Becher that students In Hard fields of study experience a heavy workload, so technology which offers affordance which save or optimise the use of time will be powerful. However from the point of view of the academic there is also a "high incidence of face to face teaching and concern for substantial coverage". Academics may be disinclined to invest large amounts of additional time preparing e-learning materials such as online tutorials if they are to be supplements to traditional activities such as large lectures, lab classes and supervision. However, they may recognise the potential gain from using Computer Assisted Assessment which could automate existing practices such as stage tests at the same time as providing students with additional opportunity for feedback.

The argument for a blended approach is that it allows the curriculum designer to systematically select those activities which best meet the range of requirements which exist supporting student learning, making good use of faculty time, and streamlining the administrative tasks which are associated with monitoring and recording student progression and achievement.

In order to further explore some of the implications suggested by the disciplinary differences matrix, it was decided to survey students across a range of academic fields of study to identify their experience of, and attitudes to, different types of e-learning interventions from each stage of the activity gradient. Their responses were then considered in the context of the knowledge matrix. Details of the survey are discussed in detail in the next section.

\section{SURVEY}

A survey of students was conducted to discover the ways elearning tools and techniques are regarded across a variety of discipline areas. The categorization developed by Neumann Beecher and Parry looked at broad subject areas. In our survey subjects were asked to identify their field of study using the categories shown below. Titles are common to subject areas in the UK.
Hard Pure: Bioscience, Earth Environment Science, Maths, Statistics, Operational Research, Physical Science

Hard Applied: Built Environments, Engineering, Health Science and Practice, Computer Science, Medicine, Dentistry and Veterinary Medicine, Psychology.

Soft Pure: Economics, English, History, Classic and Archaeology, Language Linguistics and Area Studies, Philosophical and Religious Studies, Sociology, Anthropology and Politics

Soft Applied: Art, Design and Media. Business Management and Accountancy Education Hospitality, Leisure, Sport and Tourism, Law -Dance, Drama and Music Social Policy and Social Work

A total of 286 students participated in this survey: 62 postgraduate and 224 undergraduates from different backgrounds and subject areas as detailed below (Table II).

\section{TABLE II BREAKDOWN OF SURVEY PARTICIPANTS}

\begin{tabular}{|l|l|l|}
\hline \multirow{2}{*}{ Field of Study } & \multicolumn{2}{|c|}{ Survey Participants } \\
\cline { 2 - 3 } & Undergraduate & Postgraduate \\
\hline Hard Pure & 43 & 15 \\
\hline Hard Applied & 93 & 23 \\
\hline Soft Pure & 48 & 16 \\
\hline Soft Applied & 40 & 8 \\
\hline Total & 224 & 62 \\
\hline Grand Total & 286 & \\
\hline
\end{tabular}

The institution is a traditional research intensive university in the UK. Much of teaching is on campus although e-learning is well established and use of a technology in a blended approach is widespread.

Unlike their North American counterparts the student experience is typically concentrated within a limited academic area. The vast majority of students take single honours degrees and most joint honours degrees are undertaken within cognate fields of study. Specialist study begins in year 1 . Some options outside the main specialism may have been studied but this will form a minority of the experience.

The survey asked students to identify which e-learning methods they had used and were using in relation to their current area of academic study. They were also asked which e-learning methods had been used by their lecturers and other teachers. Respondents were asked to rate their perception of the usefulness of the methods on a five point Lickert Scale. The e-learning methods were clustered under the six headings identified via the activity gradient previously described. Respondents were then asked to identify which, if any, of the types of e-learning methods they had not been exposed to, they considered would make a useful addition to the support of their learning. There were two questions which asked questions about specific technology options which have been attracting discussion in the university; a) Would you like the chance to follow lectures from the comfort of your own room, instead of going to classes? and b) Would you like to have more materials such as on-line tests for feedback on your progress? Respondents were also given the opportunity 


\section{Session S3J}

to add comment in free format on any issues raised by the questionnaire.

Among the 286 students interviewed, $87 \%$ were regular computer users able to install new packages and transfer data between packages. Generally students identified preferences to technology which afforded activities identified closely with the knowledge perspectives of their fields of study. An overview of the responses distinguishing between those in Hard and Soft areas are shown below.

\section{I 'Hard' Subjects}

More than a quarter (27\%) of all students expressed a desire to follow lectures from home. Some students even suggested recording lectures so that students can replay them for revision purposes or if a lecture was missed. There was no desire to entirely abandon the lecture system.

- Virtual Learning Environments: In general, Hard Applied found the use of VLEs useful as containers of online testing for exams and testing. Amongst medical students (Hard Applied) who had direct experience of VLEs, most (76\%) the students in this study area wanted online electronic learning to be an integral part of their degree along with computer-based presentations and assessment materials.

- Assessment: Of students studying Hard Applied subjects (113), 98\% said they would like more online tests, while $26 \%$ identified the need for more online materials for their subject. They also expressed a desire for more interaction in the classroom for example via interactive tests, so that both teacher and student can see if the subject was fully understood. Students in Hard Pure subjects did not seem to prefer online tests. Only $15 \%$ of the 58 students who took the survey stated that it would have been useful for exams. $25 \%$ of the 21 physics and mathematics students also showed an interest in computer-aided assessment materials, as some subjects require solving exercises quickly and precisely, by visualising the problem.

- Visualizations: Most respondents from the Hard Pure area $(89 \%)$ replied that they would like more computerbased learning materials to help visualise problems. Half of the 21 bioscience and environmental science students believed that more computer-based presentations and simulated environments would be useful in their subject. Students in this subject area in general liked the idea of being able to follow lectures from home, although some commented that it would be good to be able to interact with the environment more directly, in opposition to a conventional lecture (in the jungle or under the sea were given as examples). The emphasis shown here on visualisation supports the suggestion that visualisation of problems is effective for Hard Pure subjects.

\section{Soft Subjects}

Students in Soft Pure subjects seemed to prefer online teaching in the form of discussion, simulated environments and online tests. $30 \%$ of the 64 students who took the questionnaire seemed to prefer to have the chance of having online tests in order to practise subject areas for their exams. They also found the idea of having lectures from home appealing as if they were learning a new language or history it would be useful to be able to watch documentaries.

- Simulated Environments: In students belonging to the Soft Applied subjects the response was unanimous: all preferred online simulation, in particular, role-playing games. $86 \%$ of the 48 students who responded said that they would not like the chance to attend lectures from home, as in some classes live discussion takes place. Possibly this could be replaced by online discussion but they did not seem enthusiastic about the idea. It was noted that 12 economic students found simulated environments useful, and that it helped them to have a deeper or more practical approach to the subject. They pointed out that similar techniques were used in class, although with little success, as it took a long time to understand. The 13 Law students expressed a desire for more online role-playing games. This strong desire for online simulations and roleplaying games supports the categorisation theory, which recommends the use of such simulations as effective elearning techniques for teaching these subjects.

- Discussions Online: amongst the small number of Soft Pure (Philosophical and Religious Studies) respondents 5 students suggested online discussion were useful enabling discussion with other students from their own university and other universities. The 8 English students commented that online materials are used in many of their courses and that they found them very useful. From the 23 students studying Soft Applied (Linguistics and Area Studies), $89 \%$ wanted more online materials for their course as it is quite hard to find relevant information for their subject outside the university area.

\section{Responses and the knowledge framework}

The responses were broadly consistent with knowledge framework. Students in Hard areas valued items to the left of the activity gradient, reinforcing their reliance upon on facts, principles and concepts. Those from Soft areas valued items to the right of the chart which can support the development of argumentation skills and critical thinking which are core to this type of study, .

\section{Discussion}

The focus of the FIE community is evidence of an implicit, belief in the existence of disciplinary differences, and the value of sharing educational approaches within cognate areas. The implications of disciplinary differences identified by Neumann Parry and Becher [5] offer a clear framework on which one can base these intuitive understanding. Some UK researchers who have had an interest in student learning have

October 28 - 31, 2006, San Diego, CA 


\section{Session S3J}

undertaken research to look at the implications of disciplinary differences which relate to Hard fields of study. Entwistle has been concerned with students' styles of learning and the broader process of learning and teaching in Higher Education. Recently he has been examining disciplinary differences including studies specifically concerned with engineering education [17-19]. He emphasises the importance and value of a disciplinary level understanding. Beginning from a perspective of a single discipline Hammond has been much concerned with the use of computer mediated communication in education. He identified disciplinary differences as an important factor affecting the use and appropriateness of this technology when attempts were made to extend its use beyond the original area $[8,20]$. These insights may also be important in moving forward work on curriculum innovation. Evidence has been gathered which identifies discipline specific needs related to education development and curriculum innovation. Work with faculty to develop assessment specific to electrical and electronic engineering revealed that effective educational innovation, in this case related to assessment, needed to be initiated from the disciplinary rather than the educational perspective [21].

\section{Concluding Remarks}

This paper has analysed how knowledge of disciplinary differences can be used to inform the selection, design and integration of appropriate e-learning activities. The survey data provides a perspective on the analysis of educational approaches suitable for specific fields of study based on an understanding of disciplinary differences. It broadly identified e-learning preferences which tied in with the wider knowledge framework. Academic time is precious a disciplinary perspective on educational innovation has the potential to reap benefits in terms of student learning and curriculum innovation. The survey responses also suggest that the knowledge framework may be important in deciding whether to adopt a method which has been successful in another academic area. The understanding of disciplinary differences could be clarified with further studies which identify the technology affordances of popular e-learning tools. They may also be helpful in developing an understanding of how best to blend or order face-to face and e-learning approaches. Questions which can be addressed include

- How can insight into disciplinary differences assist the selection of effective e-learning approaches?

- How can understanding disciplinary preferences help identify ways of working with faculty to successfully embed e-learning and develop blended approaches?

- What are the technology affordances of e-learning which might best be used in engineering and its cognate areas.?

\section{REFERENCES}

[1] A. Biglan, "The Characteristics of Subject Matter in Different Academic Areas," Journal of Applied Psychology, vol. 57, pp. 195-203, 1973.

$$
\text { E. McDowell, S. White, and H. C. Davis, "Changing Assessment }
$$
Practice in Engineering: How Can Understanding Lecturer Perspectives Help?" European Journal of Engineering Education, vol. 29, pp. 173-181, 2004.

A. Biglan, "Relationships between Subject Matter Characteristics and the Structure and Output of University Departments.," Journal of Applied Psychology, vol. 57, pp. 204-213., 1973.

T. Becher, "The Significance of Disciplinary Differences," Studies In Higher Education, vol. 19, pp. 151, 1994.

R. Neumann, "Disciplinary Differences and University Teaching," Studies In Higher Education, vol. 26, pp. 136-146, 2001.

R. Neumann, S. Parry, and T. Becher, "Teaching and Learning in Their Disciplinary Contexts: A Conceptual Analysis," Studies In Higher Education, vol. 27, pp. 405-418, 2002.

C. Jones, M. Zenios, and J. Griffiths, "Academic Use of Digital Resources: Disciplinary Differences and the Issue of Progression," presented at Networked Learning, 2004.

N. V. Hammond and C. Bennett, "Using C\&IT to Support GroupBased Learning: What's Effective and How Do Disciplines Differ?" presented at Online Conferencing in the Arts and Humanities: Proceedings of HAN Conference, 2001.

N. Hammond, "Understanding Scholarly Teaching: Role of Discipline, Institution And National Context.," presented at Improving University Teaching 29th annual conference, Berne, 2004.

D. Laurillard, Rethinking University Teaching: A Framework for the Effective Use of Educational Technology. London: Routledge, 1993.

D. H. Jonasson, J. T. Mayes, and R. McAleese, "A Manifesto for a Constructivist Approach to Uses of Technology in Higher Education," in Designing Environments for Constructivist Learning, T. M. Duffy, J. Lowyck, and D. H. Jonassen, Eds. Berlin: Springer Verlag, 1993, pp. 231-247.

Knuth and Cunningham, "Tools for Constructivism. In," in The Design of Constructivist Learning Environments., T. Duffy, J. Lowyck, and D. Jonassen, Eds. Heidelberg: Springer-Verlag, 1993.

R. Schank and C. Cleary, "Engines for Education." New Jersey: Lawrence Erlbaum Associates, 1994.

J. T. Mayes, "Learning Technology and Groundhog Day," presented at Hypermedia at Work: Practice and Theory in Higher Education, University of Kent at Canterbury, 1995.

S. White and P. Maier, "Building Models Which Enable Change:

An Examination of the Teaching and Learning Technology Support Network," presented at Bringing Information Technology to Education (BITE), Maastricht, 1998.

V. Wright and S. White, "Technology and Language Learning," in Supporting Lifelong Language Learning. Theoretical and Practical Approaches, L. Arthur and S. Hurd, Eds.: Open University \& CILT, 2001.

W. W. Gaver, "Technology Affordances," presented at Proceedings of the SIGCHI conference on Human factors in computing systems: Reaching through technology, New Orleans, 1991.

N. Entwistle, "Learning Outcomes and Ways of Thinking across Contrasting Disciplines and Settings in Higher Education," Curriculum Journal, vol. 16, pp. 67-82, 2005.

N. Entwistle, J. Nisbet, and A. Bromage, "Teaching-Learning Environments and Student Learning in Electronic Engineering," presented at Third Workshop of the European Network on Powerful Learning Environments, Brugge, 2004.

N. J. Entwistle, D. Hounsell, and F. Marton, The Experience of Learning: Implications for Teaching and Studying in Higher Education. Edinburgh: Scottish Academic Press 1997, 1997. N. Hammond, "Discipline-Based Research into Learning and Teaching: A Survey," presented at International society for the scholarship of teaching and learning, Indiana, 2004. 